\title{
Trends in Subspecialization: A Comparative Analysis of Rural and Urban Clinical Education
}

Andrea L. Wendling, MD; Andrew Short MD; Fredrick Hetzel, MD; Julie Phillips, MD, MPH; William Short, MD

\begin{abstract}
BACKGROUND AND OBJECTIVES: Medical students who train in rural communities are often exposed to physicians practicing a broad scope of care, regardless of discipline. We examined how rural education is associated with practice specialization rates for students who match in primary care or general core specialties.
\end{abstract}

METHODS: We linked practice and specialty data (2016 AMA Masterfile dataset), demographics (American Medical College Application Service data), and internal college data for 1974-2011 Michigan State University College of Human Medicine graduates who received clinical education on either the Upper Peninsula (rural) or Grand Rapids (urban) campuses. Current practice was verified using internet searches. We compared specialty and practice data by rural or urban campus, controlling for multiple variables.

RESULTS: More rurally-trained graduates entered primary care (PC) residencies $(128 / 208,61.5 \%)$ than urban-trained graduates $(457 / 891,51.3 \% ; P<.01)$, with rurally-trained graduates being twice as likely to enter family medicine (FM) residencies. Most FM residents remained PC physicians (205/219, 93.6\%). Internal medicine residents were least likely to remain in primary care $(91 / 189$, 48.1\%). Of the general core disciplines, general surgeons were least likely to remain in general surgical practice $(45 / 134,33.6 \%)$. Within each PC or general core discipline, the proportion of graduates who specialized did not differ by type of campus.

CONCLUSIONS: Rurally-trained graduates are more likely to practice primary care, chiefly due to increased likelihood of choosing a FM residency. Graduates entering PC or general core residencies subspecialize at similar rates regardless of rural or urban education. FM residency match rate may be the best predictor of long-lasting impact on the primary care workforce.

(Fam Med. 2020;52(5):332-8.)

doi: $10.22454 /$ FamMed.2020.182557

Published Online First March 17, 2020

$\mathbf{T}$ he United States is experiencing a persistent shortage of primary care providers, particularly in rural communities. ${ }^{1}$ The rural shortage of physicians continues to have a major impact on access to care for those living in these communities, who tend to be older, sicker, and poorer, with less access to mental health services. ${ }^{2,3}$ This issue is becoming more acute as a large and disproportionate number of rural primary care physicians approach retirement. ${ }^{4}$ Many rural communities are also experiencing shortages of physicians in other broad-based specialties, such as obstetrics and gynecology, general surgery, and psychiatry. ${ }^{5-10}$

Medical schools have an impact on the rural and primary care physician workforce. Studies on educational interventions to increase numbers of physicians practicing in rural areas have consistently supported two medical school educational interventions: selective admission of students of rural origin, especially those with rural intent for practice; and rural clinical opportunities, with longer exposure more strongly associated with rural practice. ${ }^{11-18}$ Programs that employ these educational interventions have reported both a higher proportion of primary care graduates and a greater likelihood of eventual rural practice among all graduates. ${ }^{19,20}$

Although studies have demonstrated an increase in primary care specialties among graduates of rural programs, less is known about the impact of rural clinical training on other disciplines. Receiving more generalist-based training in any specialty, such as would typically

From the Department of Family Medicine, Michigan State University College of Human Medicine, East Lansing, MI (Dr Wendling and Dr William Short); Departments of Internal Medicine and Pediatrics, University of North Carolina, Chapel Hill (Dr Andrew Short); Department of Internal Medicine, Case Western Reserve University - MetroHealth, Cleveland, OH (Dr Hetzel); and Sparrow-MSU Family Medicine Residency Program, Michigan State University College of Human Medicine, Lansing, MI (Dr Phillips). 
occur in a rural training site, may influence the proportion of students who eventually have a broad scope of practice within any discipline, as opposed to those who pursue more focused subspecialization.

Our objective was to examine the residency choice, specialization, and practice patterns of 40 years of graduates of two regional campuses of Michigan State University College of Human Medicine (MSUCHM): the Upper Peninsula (UP) campus, where students receive 2 years of clinical training in a rural setting, and the Grand Rapids campus, where training is completed in a large metropolitan tertiary care health system. We specifically sought to determine how training in a rural location impacted likelihood of pursuing subspecialization after generalist residency training, including primary care specialties or general core specialties such as general surgery, psychiatry, emergency medicine, and obstetrics and gynecology.

\section{Methods}

MSU-CHM employs a distributed, community-based model of medical education..$^{21,22}$ MSU-CHM students spend their first 2 years of medical education at one of two campuses (East Lansing, Grand Rapids) and complete training at one of seven clinical campuses located throughout the state. All students meet the same admission criteria, and campus placement occurs after admission. Students preference their campus placements and most receive their first choice. The UP regional campus is unique in that all students placed in this rural location have requested the Rural Physician Program; selection for this program includes an additional interview following medical school admission. ${ }^{19} \mathrm{~A}$ description of the Rural Physician Program has been previously published. ${ }^{19,23}$

To determine graduates' specialties and practice locations, we obtained 2016 American Medical Association (AMA) Masterfile data for all MSU-CHM graduates from 1974-2015; this data set included graduates' primary residency, secondary residency, practice location, and a self-determination of whether each physician was practicing primary care. AMA Masterfile data were supplemented with MSU-CHM matriculation and alumni databases, which include specialty match data. We linked these data sets to student demographic information obtained from the American Medical College Application Service database. We then removed all graduates who had graduated within 5 years of 2016 , in order to eliminate the effects of length of graduate medical education on outcomes.

We built two cohorts from this linked dataset. The first cohort included graduates who trained through MSU-CHM's Rural Physician Program, who completed thirdand fourth-year clinical education in the rural UP. ${ }^{19,23}$ The second cohort included graduates who completed their third- and fourth-year education on MSU-CHM's Grand Rapids campus (GR). MSU-CHM's GR campus is embedded in a large tertiary care medical system located in the second-largest metropolitan statistical area in Michigan. ${ }^{24}$

For each graduate we first identified a match specialty. If a graduate did not match at time of graduation, and AMA data confirmed that the graduate completed a residency, we reassigned the residency specialty as the graduate's match specialty. Likewise, if a graduate matched into a transitional or preliminary residency position, we instead used the graduate's main AMA specialty as match specialty. A few graduates, especially before 1985, had "general practice" listed as match specialty and/or primary AMA specialty. For the purpose of this study, we included these graduates in the family medicine category. Likewise, "general medicine" graduates were included in the internal medicine category. A few graduates completely changed disciplines, such as changing from general surgery to psychiatry; these graduates were identified as changing disciplines, and, for the remainder of the analysis, were included within their new discipline.

Next, physicians were classified into three specialty groups: primary care, general core specialties, and focused specialties. We defined primary care to include family medicine, pediatrics (Peds), internal medicine (IM), internal medicine/ pediatrics (IM/Peds), or general practice, without further subspecialization. Specifically, if these graduates listed a secondary specialty in the AMA Masterfile database, they were excluded from the primary care group, with the exception of physicians who specialized in age-specific specialties (such as geriatrics) and also self-identified as practicing primary care ${ }^{19,25}$ We defined general core specialties as those typically included within required medical school coursework that did not require postresidency subspecialization, and included general surgery, obstetrics and gynecology, psychiatry, and emergency medicine within this group. All other specialties were considered focused specialties. Graduates who matched into a primary care or general core specialty and did not identify a secondary residency on the AMA Masterfile database were cross checked with internet searches to confirm they had not specialized further.

In order to determine current practice specialty, we verified AMA practice data by performing an internet search of every graduate, identifying whether stated specialty correlated with each graduate's actual practice. For instance, if a physician completed a family medicine residency program, yet had limited his or her practice only to a specific discipline such as sports medicine or hospitalist care, we assigned a practice specialty of sports or hospital medicine and removed them from the primary care category. If a physician had received extra training, but still maintained a primary care practice, they remained in the primary care category. Similarly, if a general surgeon received additional training in vascular surgery for example, yet 
was practicing as a general surgeon, he or she remained in the general core specialty of general surgery. If the surgeon had instead limited his or her practice to vascular surgery, we assigned a practice specialty of vascular surgery. All subspecialties of focused specialties were collapsed to their most general specialty category for analysis (eg, neuroradiology was included in the radiology category). After internet searches, if the assigned researcher was either unclear of a graduate's practice specialty or if the search identified a practice specialty that would not have been predicted based on the original match, the research team reviewed the original search and discussed the specialty decision until consensus was reached.

We compared rural (Upper Peninsula) and urban (Grand Rapids) campus graduates for each of the outcomes of interest: match specialty, practice specialty, match specialty group (primary care, general core, or focused specialties), and practice specialty group. We used t tests for comparison of continuous numerical variables; we used $\chi^{2}$ tests (or Fisher exact tests where appropriate) for comparisons of categorical variables, and we set significance at $P<.05$.

We then generated logistic regression models to assess the impact of multiple factors on the likelihood of a graduate entering a primary care residency; a graduate practicing primary care if original match was IM, Peds, or IM/Peds; and a graduate practicing in a comprehensive scope of practice consistent with their discipline if original match was one of the general core specialties. Each model controlled for campus type (rural, urban), sex, age, race (URM status, no URM status), state of origin (Michigan, other), and geographical origin (rural, urban). We excluded family medicine matched graduates from the PC practice logistic regression model in order to more accurately explore campus effect on specialization after completing a primary care residency; this was done because nearly all FM matched graduates remained in primary care. We designated graduates as having a rural origin if their county zip code, as reflected on their American Medical College Application Service application, had a Rural Urban Continuum Code of 4 or greater. ${ }^{26}$ We described longitudinal trends in specialty and practice patterns using graduation year as a continuous variable, and we conducted all analyses using SPSS Statistical Software Version 22 (IBM SPSS Inc, Armonk, NY).

The MSU Institutional Review Board determined that this study was non-human subjects research.

\section{Results}

Our original merged data set included 1,104 graduates: 895 had completed clinical clerkships on the urban Grand Rapids campus (GR) and 209 had completed clinical training in the rural Upper Peninsula of Michigan (UP). After excluding graduates who had never entered residency, 891 graduates remained in the Grand Rapids-trained cohort (99.6\%) and 208 remained in the Upper Peninsula-trained cohort (99.5\%).

The two cohorts did not significantly differ by gender, age, or in-state residence. The cohort of graduates trained in the Upper Peninsula was less racially diverse than the cohort of graduates trained in Grand Rapids (Table 1). UP graduates were also more likely to come from rural communities than Grand Rapids graduates.

The distribution of graduates who entered primary care and focused specialty residencies was significantly different between the Grand Rapids- and Upper Peninsula-trained cohorts, with more UPtrained graduates entering primary care residencies $(128 / 208,61.5 \%)$ than GR graduates (457/891, 51.3\%; $P<.01)$ and more GR-trained graduates entering focused specialty residencies $(144 / 891,16.2 \%)$ than UP graduates $(13,6.3 \% ; P<.01)$. There was no significant difference between the proportion of GR and UP graduates entering general core specialty residencies (GR 290/891, $32.5 \%$; UP 67/208, 32.2\%; $P=.99$ ). The largest difference between rural and urban training pertaining to residency choice was in family medicine: graduates from the rural campus were twice as likely to enter family medicine residency programs, compared to the urban campus (GR 142/891, 15.9\%; UP 77/208, 37.0\%; $P<.01)$. The proportion of UP graduates entering internal medicine residencies was about a third less than GR graduates, which was also a significant difference (GR 164/891, 18.4\%; UP 25/208, $12.0 \%$; $P=.04)$. See Table 2 for complete data regarding match specialty.

Table 2 also describes the final practice specialties of graduates. The vast majority of graduates entering family medicine residencies had remained primary care physicians (205/219, 93.6\%), regardless of rural or urban training site. As a group, internal medicine residency entrants were the least likely of the primary care residency entrants to have remained in primary care $(91 / 189$, $48.1 \%)$. Of the graduates matching into pediatrics, $65.9 \%$ (87/132) remained in primary care practice, and $57.8 \%(26 / 45)$ of graduates matching into internal medicine/pediatrics residencies practiced primary care. Of the general core disciplines, general surgeons were the least likely to remain in general practice (45/134, $33.6 \%$ ). The only primary care or general core discipline to show an increase in numbers from residency entry to practice was emergency medicine, which increased by $15.5 \%$ $(11 / 71)$; this increase was entirely due to physicians from primary care disciplines eventually focusing their practice on emergency medicine. For each primary care or general core discipline, the proportion of graduates who practiced as comprehensivists within their specialty, rather than subspecializing or practicing in a focused area, did not differ by type of clinical training campus (Figure 1).

We built logistic regression models to assess the impact of multiple 
Table 1: Comparative Matriculation Demographics of 1974-2011 Michigan State University College of Human Medicine Graduates Educated on Either the Grand Rapids (Urban) or Upper Peninsula (Rural) Clinical Campuses

\begin{tabular}{|c|c|c|c|}
\hline & $\begin{array}{c}\text { Grand Rapids Campus } \\
\text { (Urban) } \\
\text { N=891 } \\
\text { n (\%) }\end{array}$ & $\begin{array}{c}\text { Upper Peninsula Campus } \\
\text { (Rural) } \\
\mathbf{N}=208 \\
\text { n (\%) }\end{array}$ & $P$ Value * \\
\hline $\begin{array}{l}\text { Gender } \\
\text { Female } \\
\text { Male }\end{array}$ & $\begin{array}{l}407(45.7 \%) \\
484(54.3 \%)\end{array}$ & $\begin{array}{c}99(47.6 \%) \\
109(52.4 \%)\end{array}$ & .617 \\
\hline Age (mean [SD]) & $24.42(3.43)$ & $24.46(3.54)$ & .827 \\
\hline $\begin{array}{l}\text { Race } \\
\text { American Indian or Alaskan } \\
\text { Asian or Pacific Islander } \\
\text { Black } \\
\text { Hispanic } \\
\text { White } \\
\text { Did not answer }\end{array}$ & $\begin{array}{c}5(0.6 \%) \\
51(5.7 \%) \\
69(7.7 \%) \\
51(5.7 \%) \\
711(79.8 \%) \\
4(0.4 \%)\end{array}$ & $\begin{array}{c}3(1.4 \%) \\
2(1.0 \%) \\
0 \\
2(1.0 \%) \\
200(96.2 \%) \\
1(0.5 \%)\end{array}$ & $<.01$ \\
\hline $\begin{array}{l}\text { Geography of Birth County } \\
\text { Rural } \\
\text { Urban } \\
\text { Unknown }\end{array}$ & $\begin{array}{l}90(10.1 \%) \\
686(77.0 \%) \\
115(12.9 \%)\end{array}$ & $\begin{array}{c}80(38.5 \%) \\
111(53.4 \%) \\
17(8.2 \%)\end{array}$ & $<.01$ \\
\hline $\begin{array}{l}\text { State of Legal Residence } \\
\text { Michigan } \\
\text { Other } \\
\text { Unknown }\end{array}$ & $\begin{aligned} 688 & (77.2 \%) \\
88 & (9.9 \%) \\
115 & (12.9 \%)\end{aligned}$ & $\begin{array}{c}172(82.7 \%) \\
19(9.1 \%) \\
17(8.2 \%)\end{array}$ & .143 \\
\hline
\end{tabular}

* Significance calculated using $\chi^{2}$ analyses, except for age, which was calculated using independent $t$ test.

factors on the likelihood of a graduate entering a primary care residency; a graduate practicing primary care if original match was IM, Peds, or IM/Peds; and a graduate practicing in a comprehensive scope of practice consistent with their discipline if original match was one of the general core specialties. In the logistic regression model assessing the impact of factors on primary care match, campus type, gender, and URM status remained significant predictors $\left(\chi^{2}[6, \mathrm{~N}=932]=35.198, P<.001\right.$; OR rural campus 1.669; OR female 1.758; OR URM 1.831). For remaining in primary care practice, only gender remained a significant predictor $\left(\chi^{2}[6, \mathrm{~N}=307]=12.891, P=.04\right.$; OR female 1.862). For students matching into general core specialties, only older age (OR 1.121) and female gender (OR 3.167) were significant predictors of a full scope of practice $\left(\chi^{2}[6, N=293]=25.860\right.$, $P<.01)$. In summary, although type of education (rural vs urban) was a significant predictor of initial primary care residency choice, it was not significantly associated with whether physicians retained a comprehensive scope of care in either primary care or generalist core careers.

\section{Discussion}

This paper adds to the literature about the impact of rurally-based medical education on physician specialty choice and eventual scope of practice. It is unique because it explores long-term practice trends among graduates who choose primary care residencies as well as those entering other core specialties.

Graduates who train at a rural campus are more likely to enter a primary care residency and eventually practice primary care. This finding supports published literature on the impact of rural clinical training on the primary care workforce, ${ }^{17,19}$ although, similar to previous studies, causation should not be assumed because of the inherent bias that exists due to student selection of training locations.

However, we found that this increased proportion of rural campus graduates practicing primary care is almost entirely due to more rurallytrained graduates entering family medicine residencies, rather than by an increased proportion of graduates in any other discipline practicing the primary care scope of their specialty. Family physicians, regardless of training site, were significantly more likely to retain a full scope of practice than other types of primary care physicians. Graduates entering any of the primary care or general core disciplines eventually specialized at similar rates regardless of whether clinical training during medical school occurred in a rural or an urban setting. This suggests that the positive impact of undergraduate medical rural training on the primary care workforce is primarily due to graduates' increased initial choice of family medicine.

These findings were surprising, as we anticipated that students entering primary care or other core specialties such as general surgery might be more likely to remain generalists within their specialty if they 
Figure 1: Evolution From Discipline of Residency Match to Current Scope of Practice Within Specialty for Michigan State University College of Human Medicine Graduates Who Received Clinical Training on Either a Rural Campus (Upper Peninsula) or an Urban Campus (Grand Rapids)

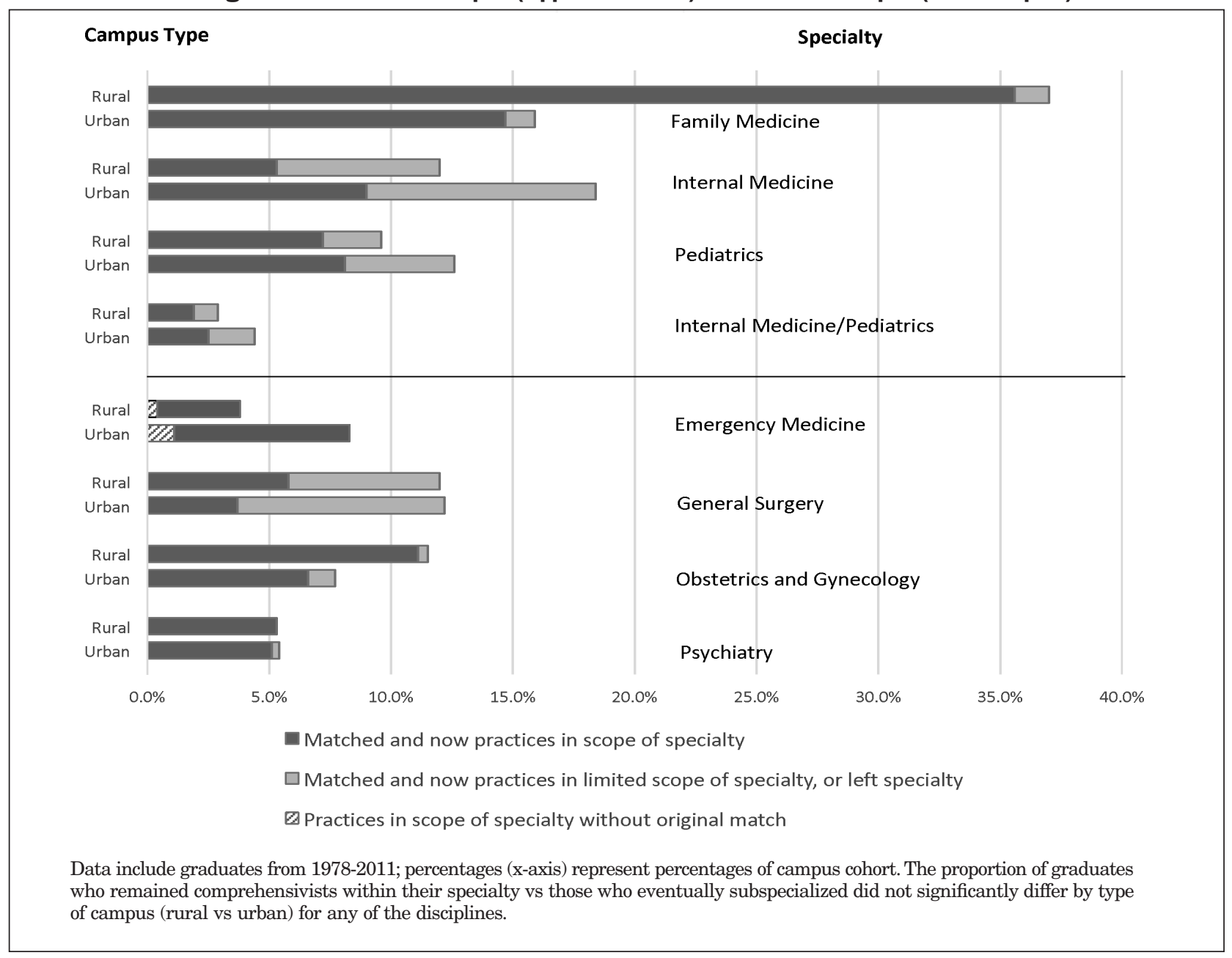

had received clinical training on a rural campus, as they would be exposed to more generalist models of practice early in their medical education careers. Since initial residency entry rates differ, but postresidency specialization rates by discipline did not differ regardless of rural or urban training, we believe that the undergraduate medical education environment may influence students' initial residency match choice, but has less of an impact on subsequent specialty decisions. Based on this finding and the well-documented need for physicians practicing the general scope of primary care and surgery, ${ }^{27}$ we feel further support for residencies that are specifically designed to support generalist practice- such as surgical rural training tracks, IM PC training tracks, or family medicine residencies-may be warranted, although evidence for this is outside the scope of our study

Half of this study's graduates matched into disciplines traditionally considered primary care, yet many of these physicians did not remain in primary care practice. Understanding this phenomenon has implications for health and educational policy and research, as reporting the traditional graduate $\mathrm{PC}$ match rate as a combination of all family medicine, internal medicine, pediatrics, and medicine/pediatrics graduates almost certainly overestimates institutions' contribution to the primary care workforce. Based on our findings, we suggest medical education programs change their current reporting practices to account for this discrepancy. This could be done by developing a formula to account for likely specialization rates of graduates, or by using practice data rather than match data to determine PC contribution.

Although this study represents 4 decades of graduates from separate regional campuses, all students were enrolled at a single institution, which limits generalizability of findings. Due to campus self-selection, students trained on the rural regional campus were more likely to be of rural origin and were less racially diverse than those trained on the urban campus, which may also 
Table 2: Initial Match Specialty and Eventual Practice Specialty for MSU-CHM Graduates From the Grand Rapids (Urban) and Upper Peninsula (Rural) Clinical Campuses, 1978-2011

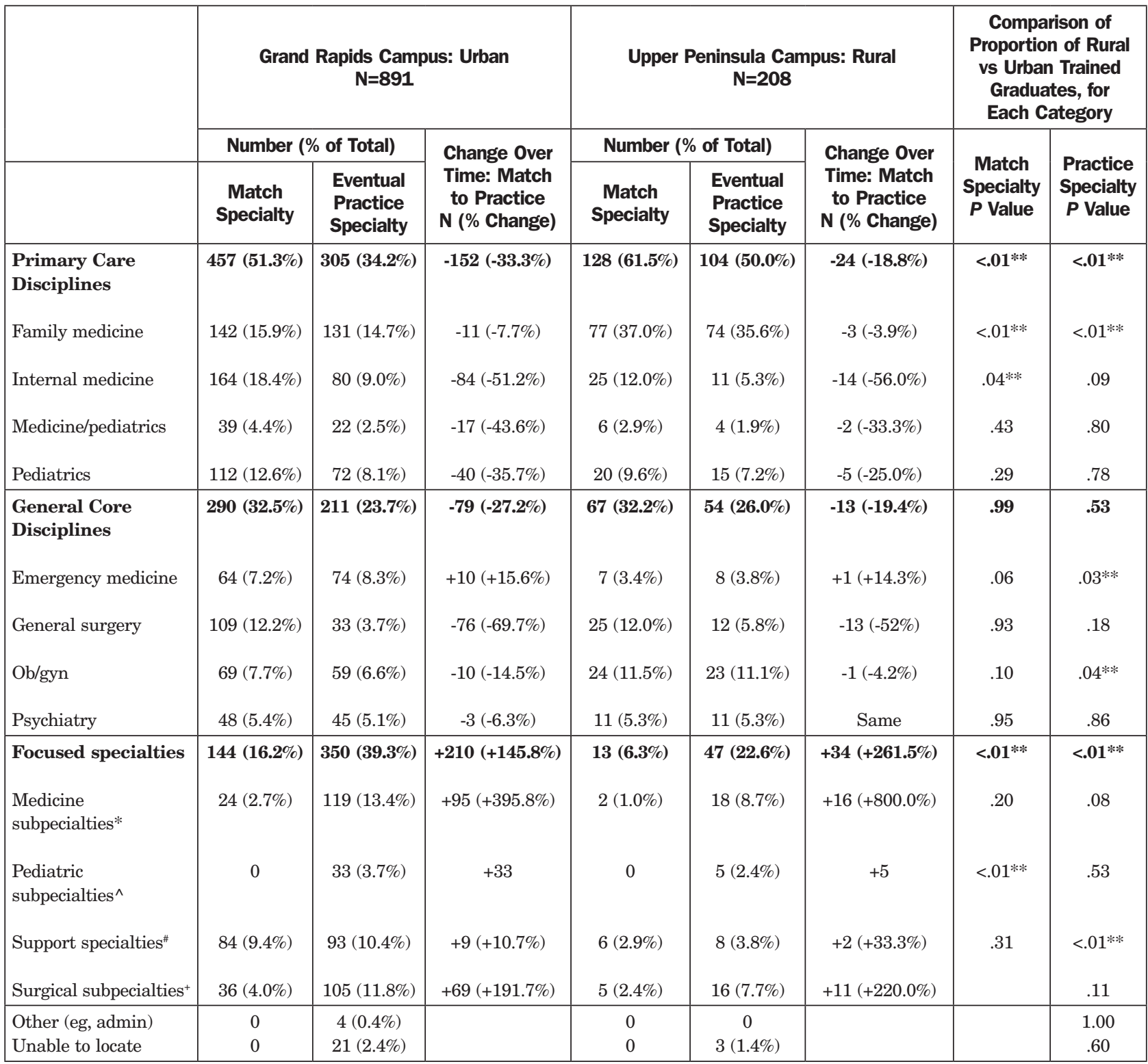

* Medicine specialties include addiction medicine, allergy and immunology, cardiology, critical care, dermatology, endocrinology, gastroenterology, genetics, hematology/oncology, hospitalist, infectious disease, neurology, occupational medicine, pain medicine, palliative medicine, physical medicine and rehabilitation, preventive medicine, pulmonology, rheumatology, sleep medicine, and sports medicine.

+ Surgical specialties include bariatric surgery, breast surgery, cardiovascular surgery, colon and rectal surgery, gynecological oncology, hand surgery, maternal fetal medicine, neurosurgery, ophthalmology, orthopedic surgery, otolaryngology, pathology, plastic surgery, surgical critical care, spine surgery, surgical oncology, thoracic surgery, urology, and vascular surgery.

\# Support specialties include anesthesiology, radiology, and subspecialties of these disciplines.

^ Pediatric specialties include neonatology, cardiology, critical care, endocrinology, gastroenterology, hematology/oncology, hospitalist, neurology, perinatology, and physical medicine and rehabilitation.

** Significant difference, $P<.05$. 
have contributed to outcomes. The subspecialization rate for internal medicine graduates in this school's cohort is much lower than what is seen nationally, ${ }^{28,29}$ which also may limit generalizability. Finally, caution should be used when interpreting findings, as the sample size for this descriptive study was not large enough to accept the null hypotheses.

Further studies combining data from multiple institutions are needed to explore whether these initial findings are reproducible. If so, the results suggest that rural medical education programs influence initial specialty choice of graduates, but have less impact on subsequent subspecialization. Additionally, medical schools, regional campuses, or other educational programs that demonstrate high numbers of graduates entering family medicine-regardless of model of training-will have the most positive impact on the primary care physician workforce, an important distinction in the contemporary context: less than $10 \%$ of US allopathic medical students currently enter family medicine residency training. ${ }^{30}$ MSU-CHM's Rural Physician Program, which includes a mission-fit selection process and substantial clinical training in a rural region, ${ }^{19}$ is one such successful model.

PREVIOUS PRESENTATIONS: Portions of this study were presented at the following conferences:

Association of American Medical Colleges Health Workforce Research Conference. Tysons Corner, VA. May 2018.

Michigan Center for Rural Health Student and Resident Rural Health Research Day. Mt Pleasant, MI. May 2018.

North American Primary Care Research Group Annual Conference. Montreal, Canada. November 2017.

CORRESPONDING AUTHOR: Address correspondence to Dr Andrea Wendling, $223 \mathrm{~N}$ Park St, Boyne City, MI 49712. 231-675-2245. wendli14@msu.edu.

\section{References}

1. Doescher MP, Skillman SM, Rosenblatt RA. The Crisis in Rural Primary Care. WWAMI Rural Health Research Center Policy Brief. April 2009.
2. Singh GK, Siahpush M. Widening rural-urban disparities in life expectancy, U, 1969-2009. Am J Prev Med. 2014;46(2):e19-e29.

3. Whitcomb ME. The challenge of providing doctors for rural America. Acad Med. 2005;80(8):715-716.

4. Fordyce M, Doescher MP, Skillman SM. The aging of the rural primary care physician workforce: will some locations be more affected than others? WWAMI Rural Health Research Center Final Report \#127. http://depts.washington.edu/uwrhrc/uploads/RHRC_FR127 Fordyce.pdf. Published September 2013. Accessed February 11, 2020.

5. Thomas CR, Holzer CE III. The continuing shortage of child and adolescent psychiatrists. J Am Acad Child Adolesc Psychiatry. 2006;45(9):1023-1031.

6. Merwin E, Hinton I, Dembling B, Stern S. Shortages of rural mental health professionals. Arch Psychiatr Nurs. 2003;17(1):42-51.

7. Thompson MJ, Lynge DC, Larson EH, Tachawachira P, Hart LG. Characterizing the general surgery workforce in rural America. Arch Surg. 2005;140(1):74-79.

8. Lynge DC, Larson EH, Thompson MJ, Rosenblatt RA, Hart LG. A longitudinal analysis of the general surgery workforce in the United States, 1981-2005. Arch Surg. 2008;143(4):345350.

9. MacDowell M, Glasser M, Fitts M, Nielsen K, Hunsaker M. A national view of rural health workforce issues in the USA. Rural Remote Health. 2010;10(3):1531.

10. Rayburn WF, Klagholz JC, Murray-Krezan C, Dowell LE, Strunk AL. Distribution of American Congress of Obstetricians and Gynecologists fellows and junior fellows in practice in the United States. Obstet Gynecol. 2012;119(5):1017-1022.

11. Wilkinson D, Laven G, Pratt N, Beilby J. Impact of undergraduate and postgraduate rural training, and medical school entry criteria on rural practice among Australian general practitioners: national study of 2414 doctors. Med Educ. 2003;37(9):809-814

12. Playford DE, Nicholson A, Riley GJ, Puddey IB. Longitudinal rural clerkships: increased likelihood of more remote rural medical practice following graduation. BMC Med Educ. 2015;15(1):55.

13. Wilson NW, Couper ID, De Vries E, Reid S, Fish T, Marais BJ. A critical review of interventions to redress the inequitable distribution of healthcare professionals to rural and remote areas. Rural Remote Health. 2009;9(2):1060.

14. Phillips R, Doodoo M, Pettersen S, et al. Specialty and Geographic Distribution of the Physician Workforce: What Influences Medical student \& Resident Choices? Washington, DC: The Robert Graham Center; March 2, 2009.

15. Brooks RG, Walsh M, Mardon RE, Lewis M, Clawson A. The roles of nature and nurture in the recruitment and retention of primary care physicians in rural areas: a review of the literature. Acad Med. 2002;77(8):790-798.

16. Ballance D, Kornegay D, Evans P. Factors that influence physicians to practice in rural locations: a review and commentary. J Rural Health. 2009;25(3):276-281
17. Rabinowitz HK, Diamond JJ, Markham FW, Wortman JR. Medical school programs to increase the rural physician supply: a systematic review and projected impact of widespread replication. Acad Med. 2008;83(3):235-243.

18. Deutchman M. Medical School Rural Tracks in the US: US Medical School Rural Track. Policy Brief. 2013. https://www.ruralhealthweb. org/NRHA/media/Emerge_NRHA/PDFs/RTPolicyBrief91513final.pdf. Accessed February 11, 2020.

19. Wendling AL, Phillips J, Short W, Fahey C, Mavis $\mathrm{B}$. Thirty years training rural physicians: outcomes from the Michigan State University College of Human Medicine Rural Physician Program. Acad Med. 2016;91(1):113-119.

20. Glasser M, Hunsaker M, Sweet K, MacDowell M, Meurer M. A comprehensive medical education program response to rural primary care needs. Acad Med. 2008;83(10):952-961.

21. Phillips JP, Wendling AL, Fahey CA, Mavis BE. The effect of a community-based medical school on the state and local physician orkforce. Acad Med. 2018;93(2):306-313.

22. Mavis B, Sousa A, Osuch J, et al. The College of Human Medicine at Michigan State University: expansion and reinvention. Acad Med. 2012;87(12):1705-1709.

23. Brazeau NK, Potts MJ, Hickner JM. The Upper Peninsula Program: a successful model for increasing primary care physicians in rural areas. Fam Med. 1990;22(5):350-355.

24. Michigan Metropolitan and Micropolitan Statistical Areas. Michigan Home Town Locator. https://michigan.hometownlocator.com/cities/ msa/. Published 2019. Accessed August 28, 2019.

25. Phillips J, Wendling AL, Fahey C, Mavis B. The impact of community-based undergraduate medical education on the regional physician workforce. Acad Med. 2016;91(11):S15.

26. United States Department of Agriculture Economic Research Service. Rural-Urban Continuum Codes. https://www.ers.usda.gov/ data-products/rural-urban-continuum-codes/. Accessed October 24, 2018.

27. Ellison EC, Pawlik TM, Way DP, Satiani B, Williams TE. Ten-year reassessment of the shortage of general surgeons: increases in graduation numbers of general surgery residents are insufficient to meet the future demand for general surgeons. Surgery. 2018;164(4):726-732.

28. Dalen JE, Ryan KJ, Alpert JS. Where have the generalists gone? They became specialists, then subspecialists. Am J Med. 2017;130(7):766-768.

29. Iglehart JK. Health reform, primary care, and graduate medical education. N Engl J Med. 2010;363(6):584-590

30. Phillips JP, Wendling A, Bentley A, Marsee R, Morley CP. Trends in US medical school contributions to the family physician workforce: 2018 update from the American Academy of Family Physicians. Fam Med. 2019;51(3):241-250. 